\title{
Comparison of Serum Levels of Hepcidin in Brucellosis Patients and Healthy Individuals
}

\author{
Sayed Hamid Hashemi ${ }^{1}$, Heidar Tayebinia ${ }^{2}$, Farzaneh Esna Ashari ${ }^{3}$, Farnaz Nemat Gorgani ${ }^{4, *}$ \\ ${ }^{I}$ Professor of Infectious Diseases, Brucellosis Research Center, Hamadan University of Medical Sciences, Hamadan, Iran \\ ${ }^{2}$ Professor of Biochemistry, Brucellosis Research Center, Hamadan University of Medical Sciences, Hamadan, Iran. \\ ${ }^{3}$ Associate Professor, Department of Social Medicine, School of Medicine, Hamadan University of Medical Sciences, \\ Hamadan, Iran \\ ${ }^{4}$ Resident, Department of Infectious Diseases, School of Medicine, Hamadan University of Medical Sciences, Hamadan, Iran \\ * Corresponding Author: Farnaz Nemat Gorgani, Department of Infectious Diseases, School of Medicine, Hamadan \\ University of Medical Sciences, Hamadan, Iran.Email: farnazng85@gmail.com
}

Received: 24.03 .2017

Accepted: 28.06 .2017

How to Cite this Article:

Hashemi SH, Tayebinia H, Esna Ashari F, Nemat Gorgani F. Comparison of Serum Levels of Hepcidin in Brucellosis Patients and Healthy Individuals. Sci J Hamadan Univ Med Sci. 2017; 24(3): 199-205. DOI: 10.18869/ acadpub.ajcm.24.3.199.

\section{Abstract}

Background and Objective: Hepcidin is an acute-phase protein produced by the liver, which inhibits the proliferation of pathogens by increasing iron sequestration in macrophages and decreasing iron absorption. Although several studies have been performed on the role of hepcidin, data on its role in brucellosis are scarce. The aim of this study was to compare the serum level of hepcidin in patients with brucellosis and healthy controls.

Materials and Methods: We recruited all the brucellosis patients referred to the clinic or Infectious Diseases Unit of Sina Hospital, Hamadan, Iran, from April 2016 to February 2017. The control group included age- and gender-matched individuals who visited the hospital for medical check-up examination or as patient companions. Blood samples were obtained from all the individuals and serum hepcidin level was measured using ELISA. A questionnaire on demographic characteristics and clinical symptoms and signs of brucellosis was completed for each subject. Data were analyzed using Stata 11 software.

Results: In this case-control study, 42 patients with brucellosis and 42 healthy controls were enrolled. The most common clinical symptoms of brucellosis were fever $(76 \%)$ and arthralgia (69\%). Further, Wright $>1.160$ and $2 \mathrm{ME}>1.80$ were found in $55 \%$ and $60 \%$ of the patients, respectively. Symptomatic brucellosis was detected in $12(28 \%)$ patients. The mean serum levels of hepcidin in the patients and controls were $42.6 \pm 11.7$ and 17.3 \pm 4.2 , respectively, showing that hepcidin level was significantly higher in the patient group compared to the control group $(\mathrm{P}<0.001)$. Of the 42 patients, 12 suffered from symptomatic brucellosis. The mean serum levels of hepcidin in the symptomatic and asymptomatic patients were $41 \pm 10.1$ and $43 \pm 12.4$, respectively, indicating no significant differences between the two groups in this regard.

Conclusion: Increased serum level of hepcidin in brucellosis patients can be considered as a diagnostic biomarker of inflammation and active disease. Further studies are required to identify the role of hepcidin as a host defense mechanism and its potential effect on brucellosis pathogenesis.

Keywords: Biomarker; Brucellosis; Hepcidin 
dof: $10.18869 /$ acadpub.ajcm.24.3.199

\section{مقايسه سطح سر مى هيسيدين در بيماران مبتلا به بروسلوز و افر اد سالم}

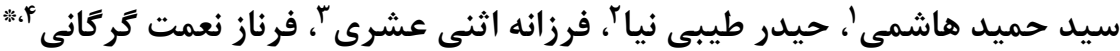

' استاد بيماريهاى عفونى، مركز تحقيقات بروسلوز، دانشعاه علوم يزشكى همدان، همدان، ايران

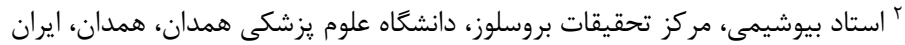

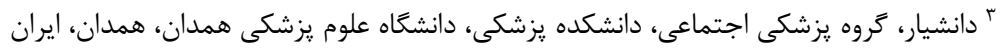

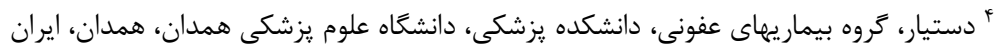

* نويسنده مسئول: فرناز نعمت كر كانى، گروه بيماريهاى عفونى، دانشكده يزشكى، دانشعاه علوم يزشكى همدان، همدان، ايران.

ايميل:gmail.com

\begin{tabular}{|c|c|}
\hline 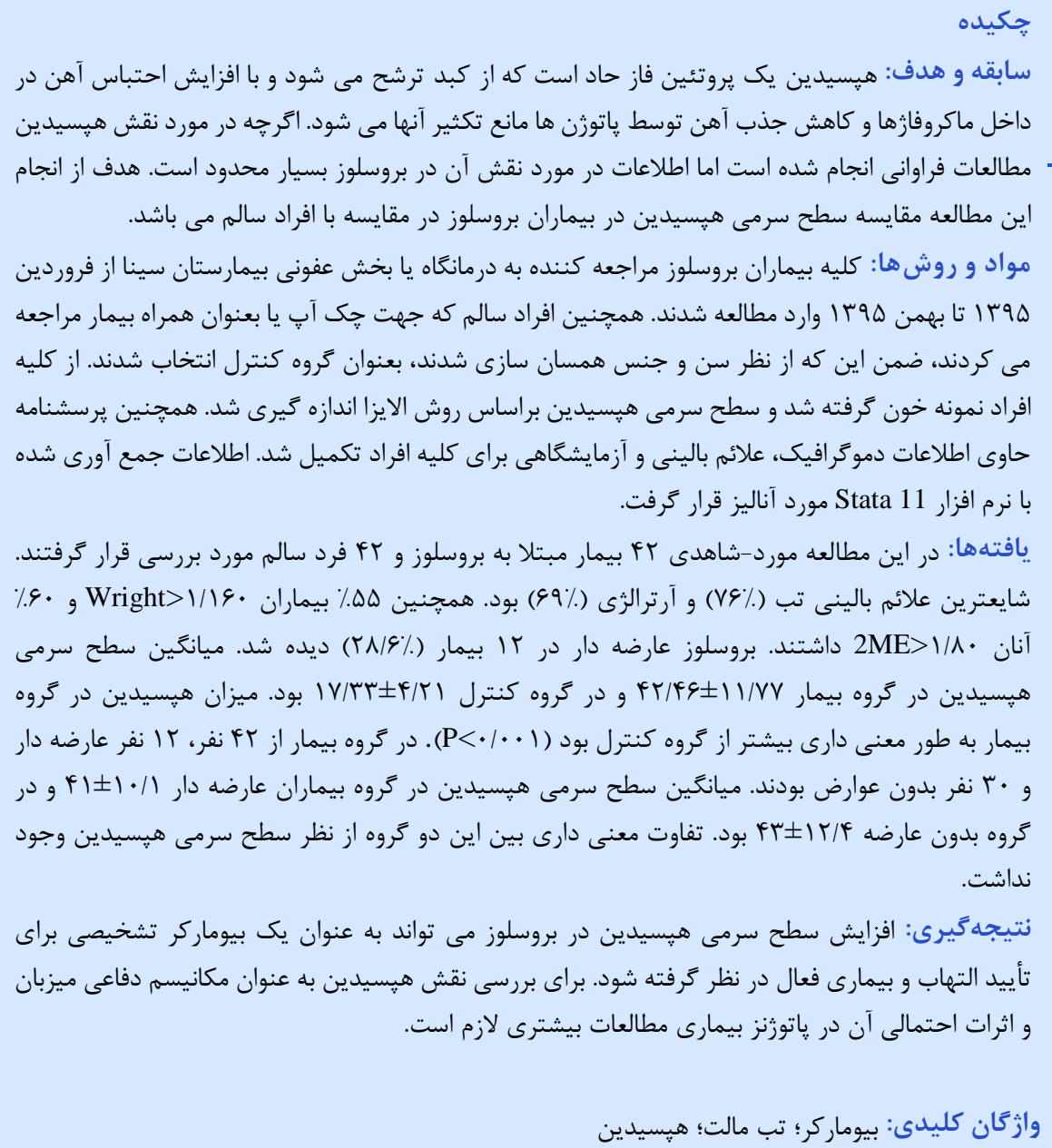 & 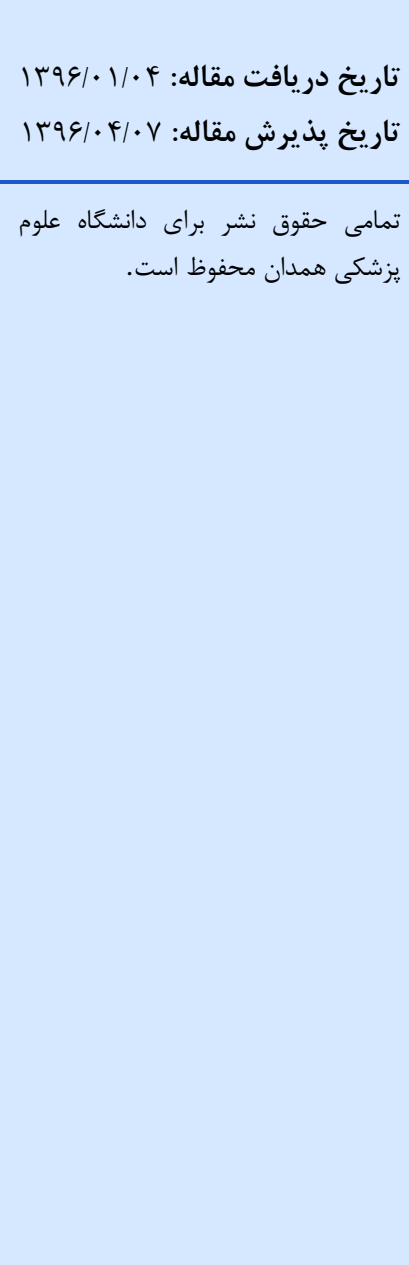 \\
\hline
\end{tabular}

مقلدمه

شامل مصرف شير و لبنيات غير ياستوريزه از قبيل ينير، بستنى

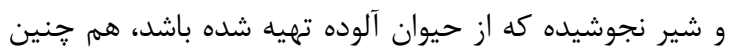

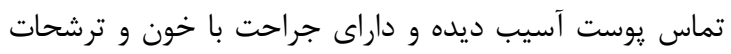

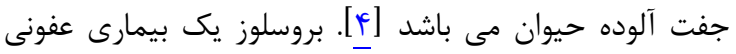
سيستميك مى باشد كه با طيف وسيعى از علايم بالينى همراه است و ار گان هاى مختلفى را مانند كبد، دستخاه گوارش، دستخاه
بروسلوز يكى ازمهمترين بيمارى هاى مشترك بين انسان و

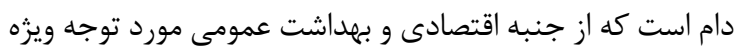
مى باشد. عامل اين بيمارى باكترى هاى كرم منفى از جنس إنس

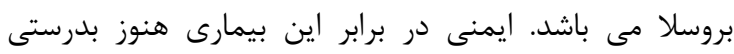

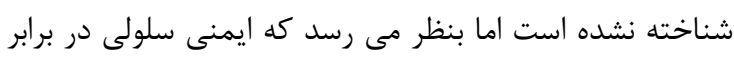

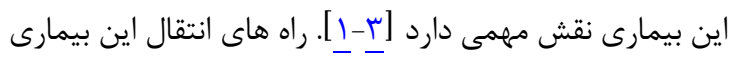


(ارديبهشت هوسا تا آذر هوץ|) به درمانگاه يا كلينيك هاى

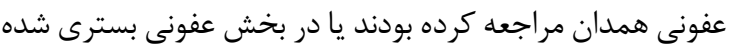

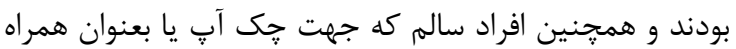

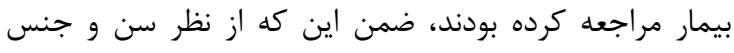

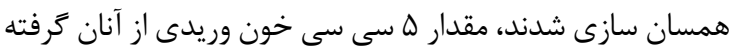

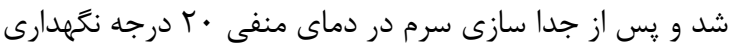

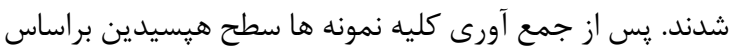

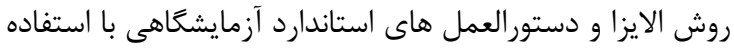
از كيت شركت R\&D Systems, USA اندازه كيرى شد. مقادير الرداي بيش از مو مثبت تلقى كرديد.

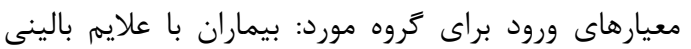
مشكوك به بروسلوز همراه با يكى از معيارهاى آزمايشگاهى: Wright $\geq 1 / \Lambda$ •

$$
\text { نمونه هاى بالينى از نظر بروسلا. }
$$

معيار هاى خروج براى گروه مورد: افرادى كه بجز برون بروسلوز

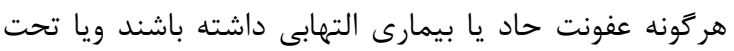
درمان با داروى ضد التهاب (استروئيدى و غير استروئيدى) باشند.

معيارهاى ورود براى گروه شاهد: افرادى كه هيجگًّنه سابقه

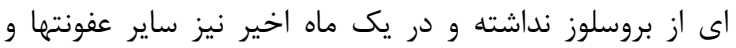
بيماريهاى التهابى را نداشته باشند. معيارهاى خروج براى گروه شاهد: داشتن سابقه بروسلوز، باندئن

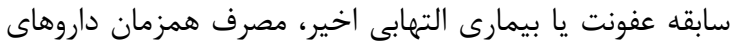

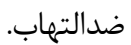
لازم به ذكر است دراين مطالعه بيمارى بروسلوز، موارد

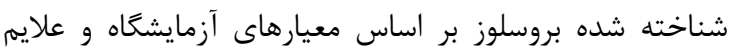

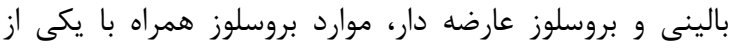

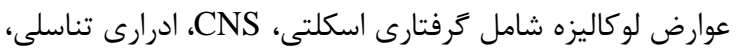

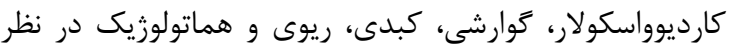
كرفته شد. داده هاى مطالعه بر اساس جكى ليست تهيه شده جمع آورى

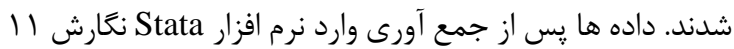

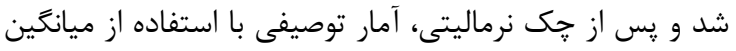

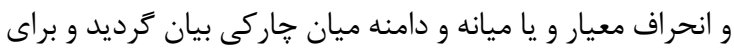

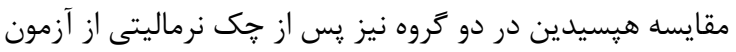
من ويتنى و يا تى تست استفاده شد.

\section{Lافته . إنه}

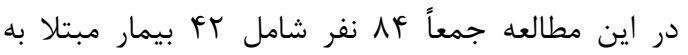

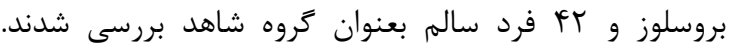

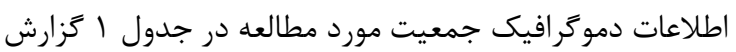

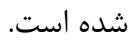

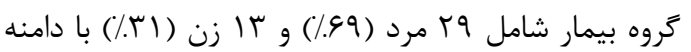
سنى Qا تا VV سال و ميانه سنى ال سال بودند. گروه كنترل
عصبى، ريه ها، دستخاه قلبى - عروقى، يوست، جشم و مفاصل

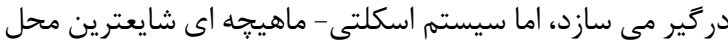
دريرى مى باشد [ه].

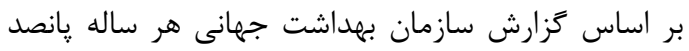

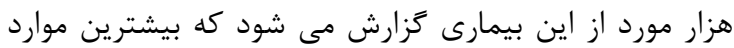

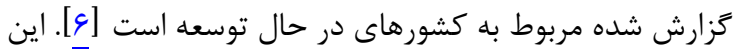

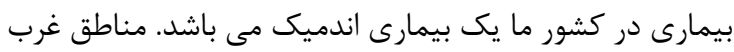

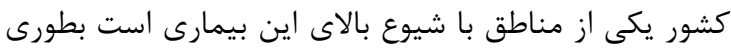

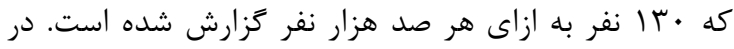
استان همدان درسال هاى اخير شيوع له

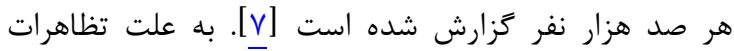

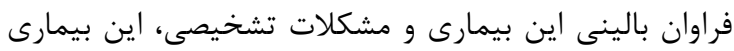

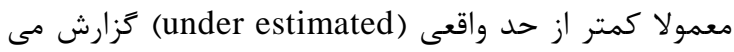
شود [1].

تغييرات مختلف آزمايشگاهى از جمله اختلالات هماتولوزيك،

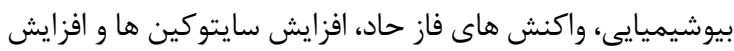

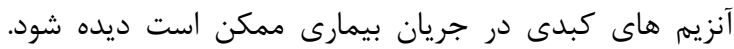

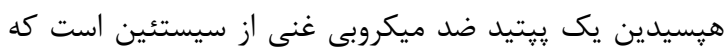

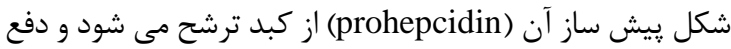

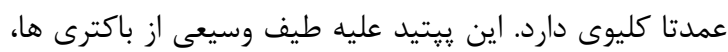

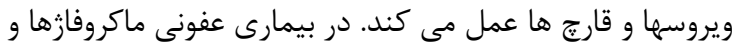

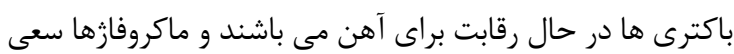

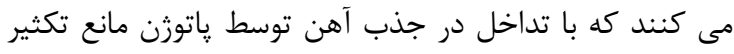

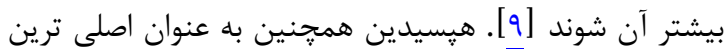

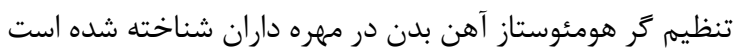

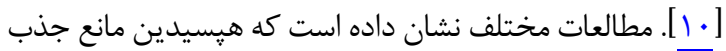

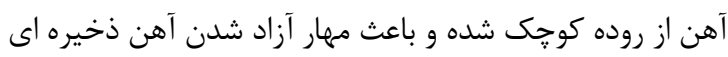

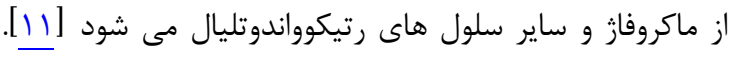

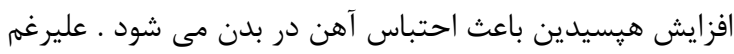

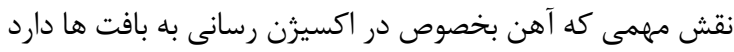

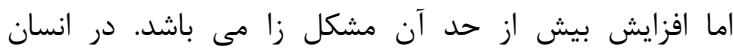

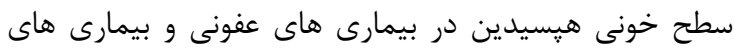

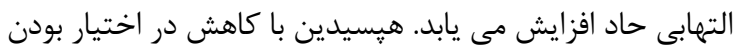
سطح آهن براى عوامل ميكروبى نقش مهرى در در ايمنى ايفا مى كند [1 اI] بر اساس اطلاعات موجود اگرجه در مورد نقش هيسيدين

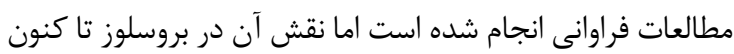
مشخص نشده است و بهمين منظور اين مطالعه با هدف مقايسه سطح سرمى هيسيدين در بيماران بروسلوز و افراد سالم انجام

\section{مواد و روشها}

يس از توضيح اهداف مطالعه و اخذ رضايت آكاهانه كتبى از كليه بيماران واجد شرايط مطالعه كه در طى انى انجام طرح 


\begin{tabular}{|c|c|c|}
\hline تروه شاهد ( F ن نفر) & تروه بيمار (FY نفر) & 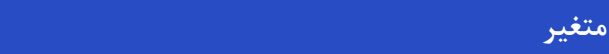 \\
\hline \multirow[t]{2}{*}{$F r / / F \pm \mid \Lambda / V F$} & $F T / / 9 \pm / N / / Q$ & ميانگَين سن: (سال) \\
\hline & & جنس : تعداد (درصد) \\
\hline$r \backslash(\Delta \cdot)$ & rq $(1.99)$ & مذكر \\
\hline \multirow[t]{2}{*}{$r I(\Delta \cdot)$} & $\|(/ / \mu)$ & 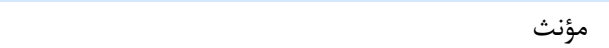 \\
\hline & & محل زندگى : تعداد (درصد) \\
\hline TA $(9 \varphi / \Lambda)$ & ५ (१५) & روستا \\
\hline \multirow[t]{2}{*}{$\mid f(r / r)$} & $r(v)$ & شهر \\
\hline & & سطح تحصيلات : تعداد (درصد) \\
\hline$T Y(\Delta T / \mathcal{F})$ & re $(9 / / 9)$ & 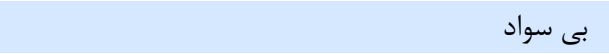 \\
\hline If $(\Psi \Psi / \Gamma)$ & If $(Y K / T)$ & دييلم \\
\hline$\varphi(\mid \mathcal{F} / \Gamma)$ & $r(\boldsymbol{\Psi} / \Lambda)$ & دانشخاهى \\
\hline rT $(V G / T)$ & rq (9r/9) & سابقه مصرف لبنيات محلى يا تماس با دام: تعداد (درصد) \\
\hline
\end{tabular}

لكوسيت كمتر از · ل هزار در محدوده نرمال يا لكوينى

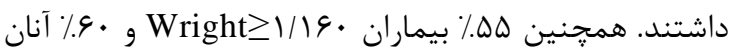

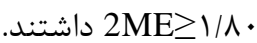

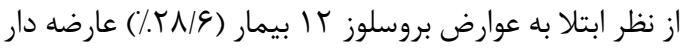

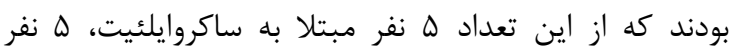

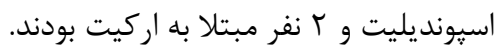

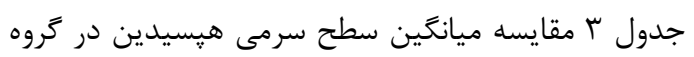

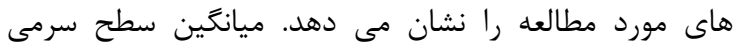

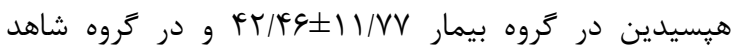

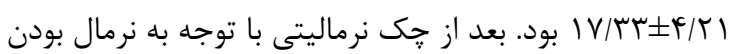

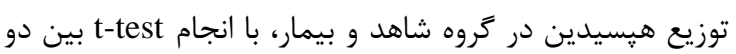

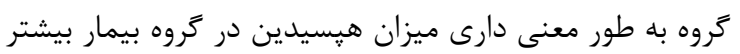

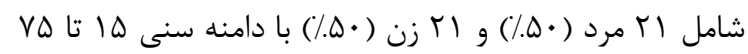

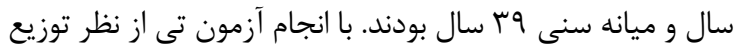

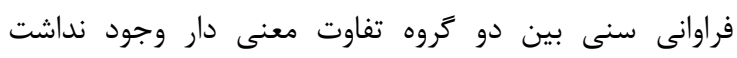

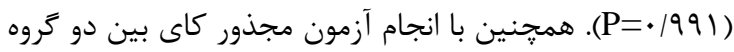

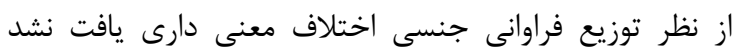
.$(\mathrm{P}=\cdot / \cdot \mathrm{V} \Delta)$

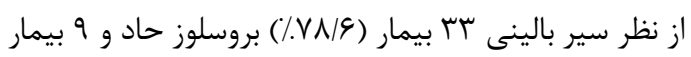

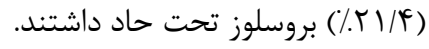

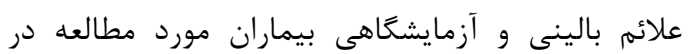

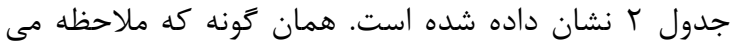

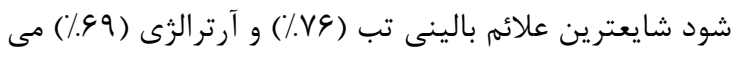

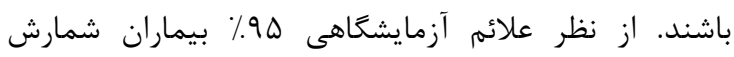
جدول r: توزيع فراوانى علائم بالينى و آزمايشگاهى بيماران مورد مطالعه

\begin{tabular}{|c|c|c|}
\hline درصد & فراوانى & علائم \\
\hline Ve & rT & نب \\
\hline 99 & rq & آرترالزى \\
\hline 91 & re & كمردرد \\
\hline$\Delta 9$ & ra & ميالزى \\
\hline$\Delta V$ & TF & بـ اشتهايى \\
\hline \multirow[t]{2}{*}{$\Delta V$} & TF & كاهش وزن \\
\hline & & تعداد لكوسيت \\
\hline$\Delta$ & r & $\mathrm{WBC}>1 \ldots$ \\
\hline 11 & ry & $\Delta \cdots \leq \mathrm{WBC} \leq 1 \cdots$ \\
\hline \multirow[t]{2}{*}{ If } & r & $W B C<\Delta \cdots$ \\
\hline & & تست سرولوزيك \\
\hline 19 & $\wedge$ & Wright $=1 / \Lambda$ \\
\hline 4. & ra & $1 / \Lambda \cdot<W B C<1 / \& 4$. \\
\hline rI & 9 & Wright $\geq 1 / \& \uparrow$. \\
\hline If & 4 & $2 \mathrm{ME}=1 / 4$. \\
\hline VT & $r$. & $1 / F \cdot<2 \mathrm{ME}<1 / \pi r \cdot$ \\
\hline If & 4 & $2 \mathrm{ME} \geq 1 / \pi r$. \\
\hline
\end{tabular}


جدول ؟ّ: مقايسه ميانََين سطح سرمى هيسيدين در كروه هاى مورد مطالعه

\begin{tabular}{|c|c|c|c|}
\hline P ارزش & ميانَين سطح هيسيدين & 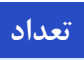 & تروه \\
\hline \multirow{2}{*}{$\cdot 1 \cdot \cdot 1$} & FT/F $\pm I I / V$ & Fr & بروسلوز \\
\hline & $\mid V / r \pm r / r$ & FT & شاهد سالم \\
\hline \multirow{2}{*}{$\cdot / r \cdot \Lambda$} & $|4| \pm 1 \cdot 11$ & ir & بروسلوز عارضه دار \\
\hline & $F r \pm I r / F$ & r. & بروسلوز بدون عارضه \\
\hline
\end{tabular}

سير بهبودى به سرعت كاسته مى شود، يافته هاى مذكور نشانكر اين است كه هيسيدين نيز به عنوان يك بهرئ يروتئين فاز

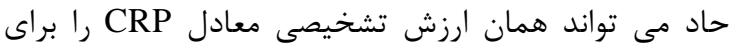

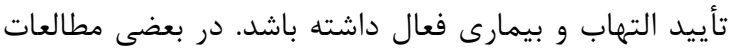

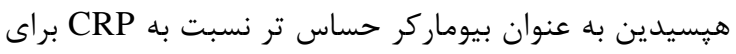

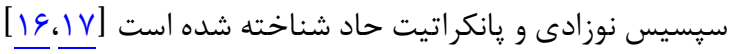

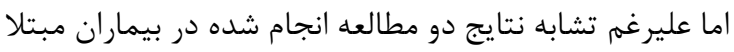

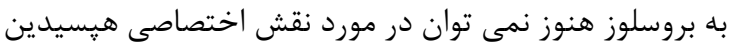
در ياتوزنز بروسلوز قضاوت كرد.

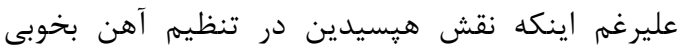

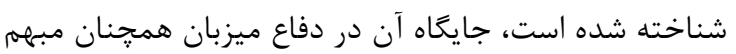

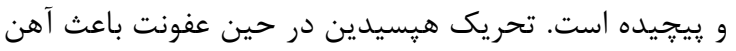

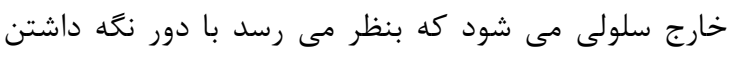

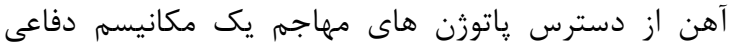

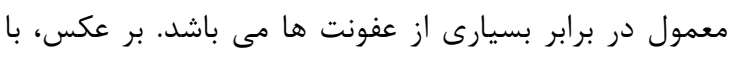

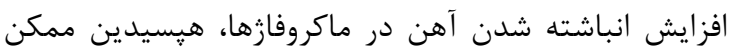

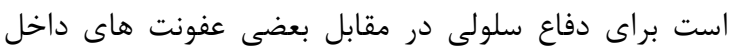

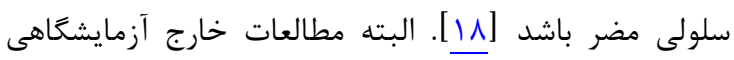

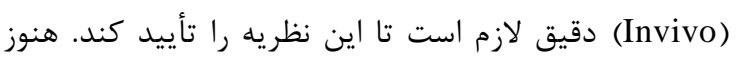

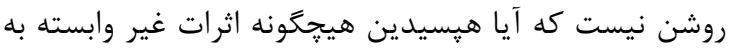
آهن بر دفاع ميزبان دارد.

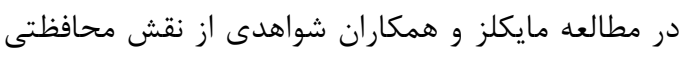

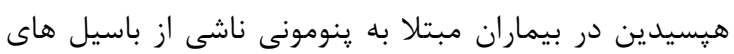

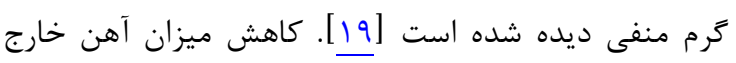

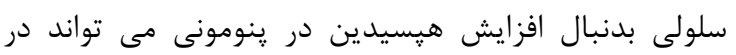

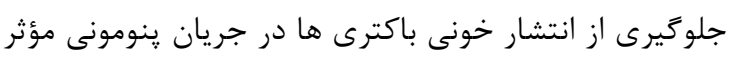

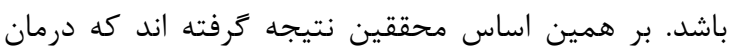

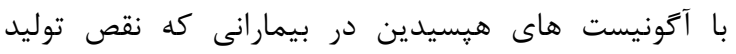

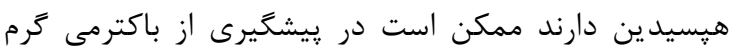
منفى در بيماران ينومونى مفيد باشد.

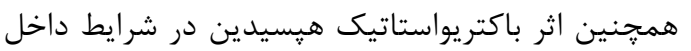

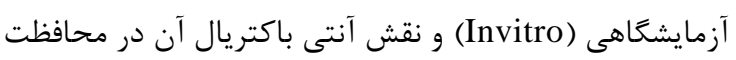

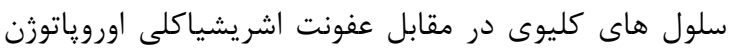

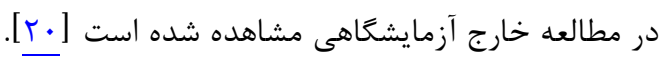

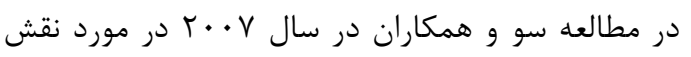

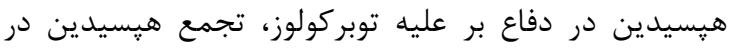

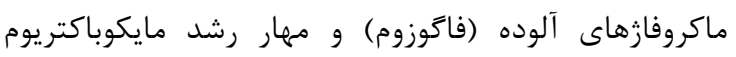

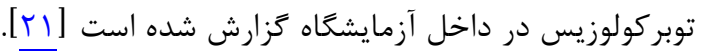

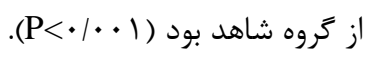

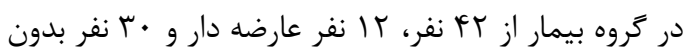

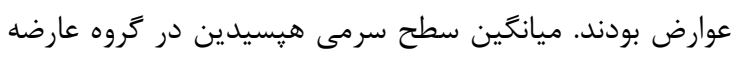

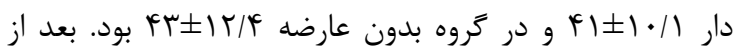

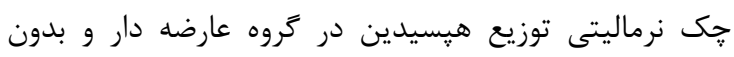

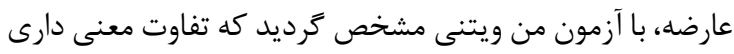

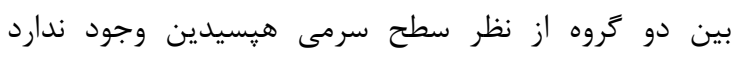
.$(\mathrm{P}=\cdot / \mathrm{r} \cdot \Lambda)$

\section{بحث} در اين مطالعه Fr F بيمار مبتلا به بروسلوز مورد بررسى

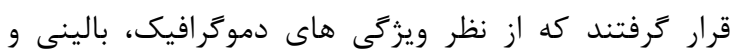

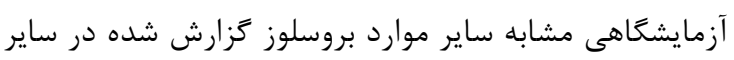

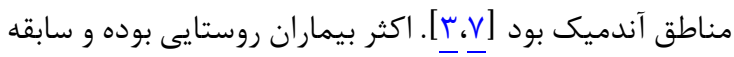

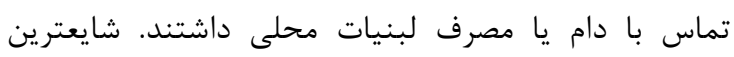

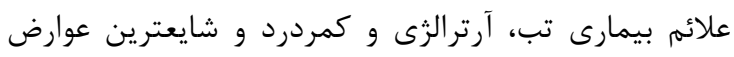
دركيرى استخوانى-مفصلى بود. با توجه به تشابه خصوصيات

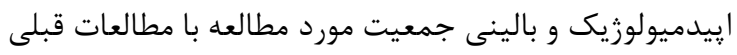

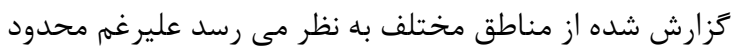

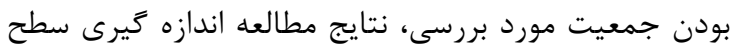

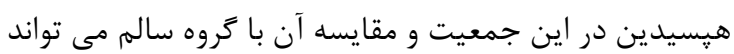
قابل تعميم به كل جامعه باشد.

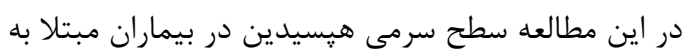

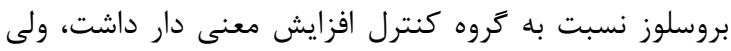

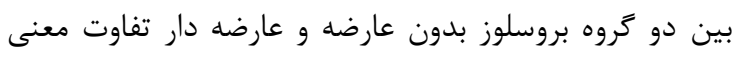

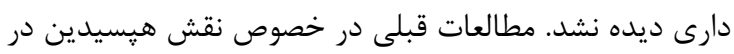

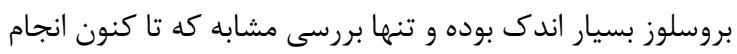

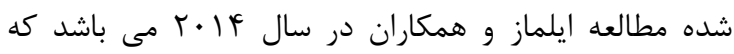

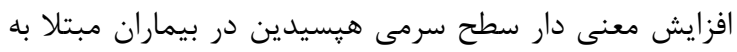

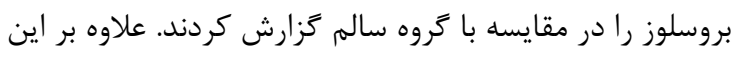

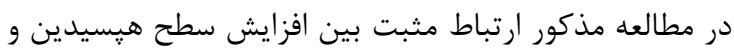
سطح CRP نيز يافت شده است [سرا].

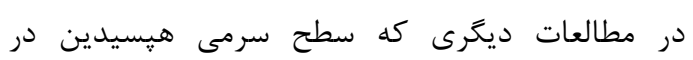

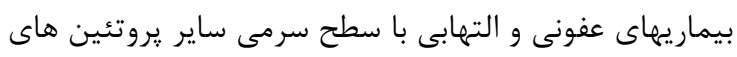

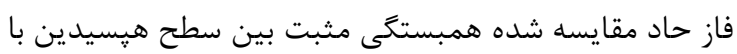

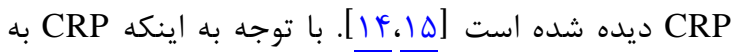

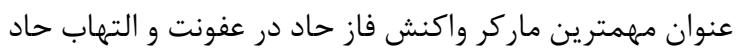

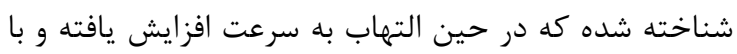




$$
\begin{aligned}
& \text { يَى بردن به نقش هيسيدين در دفاع بر عليه بروسلا و اثر آنتى }
\end{aligned}
$$

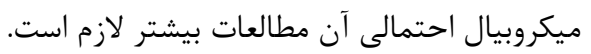$$
\text { نتيجه تيرى }
$$

افزايش سطح سرمى هيسيدين در بروسلوز مى تواند به

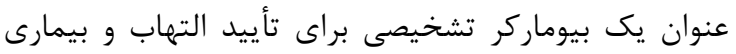

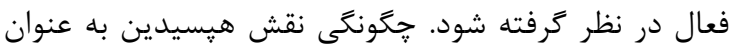

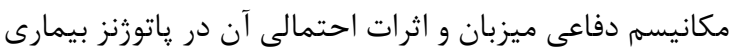

$$
\text { نياز به مطالعات بيشترى دارد. }
$$

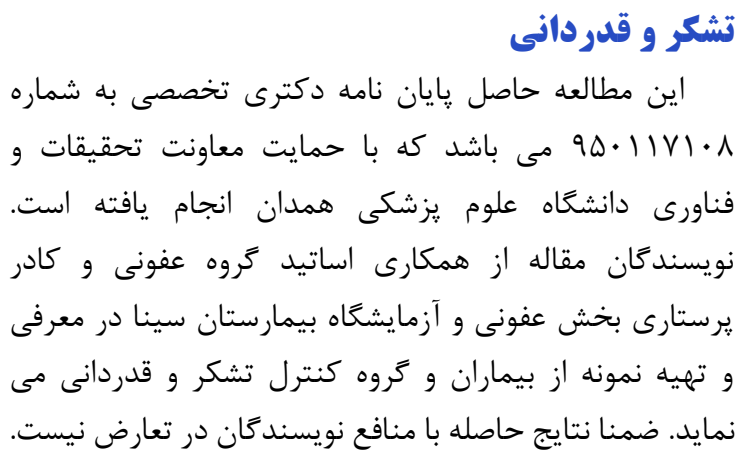

\section{REFERENCES}

1. Byndloss MX, Tsolis RM. Brucella spp. virulence factors and immunity. Annu Rev Anim Biosci. 2016;4:111-27. PMID: 26734887 DOI: 10.1146/annurev-animal-021815-111326

2. de Figueiredo P, Ficht TA, Rice-Ficht A, Rossetti CA, Adams LG. Pathogenesis and immunobiology of brucellosis: review of brucella-host interactions. Am J Pathol. 2015;185(6):150517. PMID: 25892682 DOI: 10.1016/j.ajpath.2015.03.003

3. Beeching NJ, Corbel MJ. Brucellosis. In: Kasper DL, Fauci AS, Hauser SL, Longo DL, Jameson JL, Loscalzo J, editors. Harrison's principles of internal medicine. $19^{\text {th }}$ ed. New York: McGraw Hill; 2015. P. 1-5.

4. Rubach MP, Halliday JE, Cleaveland S, Crump JA. Brucellosis in low-income and middle-income countries. Curr Opin Infect Dis. 2013;26(5):404-12. PMID: 23963260 DOI: 10.1097/QCO.0b013e3283638104

5. Gul HC, Erdem H. Brucella species. In: Mandell GL, Bennett JE, Dolin R, editors. Principles and practice of infectious diseases. $8^{\text {th }}$ ed. Philadelphia: Churchill Livingstone; 2015. P. 2584-9.

6. Musallam II, Abo-Shehada MN, Hegazy YM, Holt HR, Guitian FJ. Systematic review of brucellosis in the Middle East: disease frequency in ruminants and humans and risk factors for human infection. Epidemiol Infect. 2016;144(4):671-85. PMID: 26508323 DOI: 10.1017/ S0950268815002575

7. Zeinali M, Nabavi M, Shirzadi MR, Hajrasoliha $H$. Epidemiological situation of brucellosis in the past three decades in Iran. Iran J Public Health. 2014;43(2):24.

8. Mantur BG, Biradar MS, Bidri RC, Mulimani MS, Veerappa,

Kariholu $\mathrm{P}$, et al. Protean clinical manifestations and diagnostic challenges of human brucellosis in adults: 16 years' experience in an endemic area. J Med Microbiol. 2006;55(Pt 7):897-903. PMID: 16772417 DOI: 10.1099/ jmm.0.46097-0

9. Zhong W, Lafuse WP, Zwilling BS. Infection with mycobacterium avium differentially regulates the expression of iron transport protein mRNA in murine peritoneal macrophages. Infect Immun. 2001;69(11):6618-24. PMID: 11598030 DOI: 10.1128/IAI.69.11.6618-6624.2001

10. Armitage AE, Eddowes LA, Gileadi U, Cole S, Spottiswoode $\mathrm{N}$, Selvakumar TA, et al. Hepcidin regulation by innate immune and infectious stimuli. Blood. 2011;118(15):412939. PMID: 21873546 DOI: $10.1182 /$ blood-2011-04-351957

\begin{abstract}
همجنين در مطالعه ديخرى در سال || • إ توسط سو و
همكاران تحريك توليد هيسيدين توسط ساير سلول هاى دفاعى غير از ماكروفازها، شامل سلولهاى إيتليال آلوئول ها و مونوسيت هاى گردش خون در مواجهه با باسيل سل مشاهده شد. يافته هاى اين مطالعه اهميت هيسيدين در دفاع ميزبان در مقابل مايكوباكتريوم توبر كولوزيس را بيشتر روشن مين

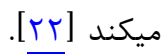

با توجه به افزايش سطح خونى هيسيدين در بروسلوز و با در نظر گرفتن اين كه بروسلا نيز يك گاتوزن داخل سلولى است

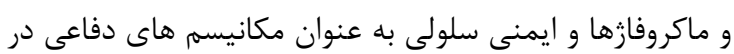
مقابل آن تحريك مى شوند، ممكن است مشابه همان نقشى كه در مطالعات مذكور براى هيسيدين در برابر مايكوباكتريوم توبر كولوزيس مشخص شده است در بروسلوز نيز مشاهده شود. از سوى ديخر، با توجه به خصوصيات منحصر بفرد بروسلا و

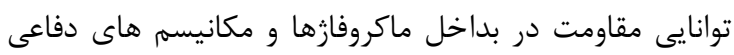
ييجيده ميزبان، هنوز در مورد ايمونوياتوزنز بروسلوز ابهامات زيادى وجود دارد. لذا نتايج مطالعات انجام شده بر روى ساير بيماى هاى عفونى را نمى توان به بروسلوز تعميم داد و براى
\end{abstract}

11. Nicolas G, Bennoun M, Porteu A, Mativet S, Beaumont C, Grandchamp B, et al. Severe iron deficiency anemia in transgenic mice expressing liver hepcidin. Proc Natl Acad Sci $U S$ A. 2002;99(7):4596-601. PMID: 11930010 DOI: 10.1073/pnas.072632499

12. Drakesmith H, Prentice AM. Hepcidin and the iron-infection axis. Science. 2012;338(6108):768-72. PMID: 23139325 DOI: $10.1126 /$ science. 1224577

13. Yilmaz E, Ayarci AO, Sigirli D, Torlar MO, Budak F, Goral $\mathrm{G}$, et al. Increased serum hepcidin levels in brucellosis. Clin Lab. 2014;60(11):1837-43. PMID: 25648024

14. Bergamaschi G, Di Sabatino A, Albertini R, Costanzo F, Guerci M, Masotti M, et al. Serum hepcidin in inflammatory bowel diseases: biological and clinical significance. Inflamm Bowel Dis. 2013;19(10):2166-72. PMID: 23867871 DOI: 10.1097/MIB.0b013e31829a6e43

15. Mogadam RA, Nemati A, Amani F, Ghorbanihaghjo A, Argani H, Bashardoust B. Association between hepcidin, haemoglobin level and iron status in stage 4 chronic kidney disease patients with anaemia. $J$ Pak Med Assoc. 2015;65(4):354-7. PMID: 25976565

16. Arabul M, Celik M, Aslan O, Torun S, Beyazit Y, Alper E, et al. Hepcidin as a predictor of disease severity in acute pancreatitis: a single center prospective study. Hepatogastroenterology. 2013;60(123):595-600. PMID: 23665668 DOI: $10.5754 /$ hge12770

17. Wu TW, Tabangin M, Kusano R, Ma Y, Ridsdale R, Akinbi $\mathrm{H}$. The utility of serum hepcidin as a biomarker for late-onset neonatal sepsis. $J$ Pediatr. 2013;162(1):67-71. PMID: 22796049 DOI: 10.1016/j.jpeds.2012.06.010

18. Michels K, Nemeth E, Ganz T, Mehrad B. Hepcidin and host defense against infectious diseases. PLoS Pathog. 2015;11(8):e1004998. PMID: 26291319 DOI: 10.1371/ journal.ppat.1004998

19. Michels KR, Zhang Z, Bettina AM, Cagnina RE, Stefanova $\mathrm{D}$, Burdick MD, et al. Hepcidin-mediated iron sequestration protects against bacterial dissemination during pneumonia. JCI Insight. 2017;2(6):e92002. PMID: 28352667 DOI: 10.1172/jci.insight.92002

20. Houamel D, Ducrot N, Lefebvre T, Daher R, Moulouel B, Sari MA, et al. Hepcidin as a major component of renal antibacterial defenses against uropathogenic escherichia coli. J Am Soc Nephrol. 2016;27(3):835-46. PMID: 26293821 
DOI: 10.1681/ASN.2014101035

21. Sow FB, Florence WC, Satoskar AR, Schlesinger LS, Zwilling BS, Lafuse WP. Expression and localization of hepcidin in macrophages: a role in host defense against tuberculosis. J Leukoc Biol. 2007;82(4):934-45. PMID: 17609338 DOI: $10.1189 / \mathrm{jlb} .0407216$
22. Sow FB, Nandakumar S, Velu V, Kellar KL, Schlesinger LS, Amara RR, et al. Mycobacterium tuberculosis components stimulate production of the antimicrobial peptide hepcidin. Tuberculosis (Edinb). 2011;91(4):314-21. PMID: 21482189 DOI: 10.1016/j.tube.2011.03.003 